\title{
Developing a new service for the digital traveler satisfaction: The Smart Tourist App
}

Federica Palumbo. Sapienza University of Rome. Italy. federica.palumbo@uniroma1.it

\begin{abstract}
The spread of digital technologies offers great potential for both the creative industries in general and for the tourism industry. The overall goal of this research is to evaluate the impact of mobile technology in augmenting and streamlining the tourist experience. To this end, we integrate two existing methodologies, the Kano Model (KM) and the Analytic Hierarchy Process (AHP), which allow categorization and ordering of service attributes according to how they are perceived by customers, and we estimate their impact on customer satisfaction. Our analysis is based on qualitative data collected through questionnaires administered to a panel of Italian tourists visiting the cities of Palermo and Rome, over a period of 3 months (March-May 2014). As results in evaluating the impact of mobile technology we propose the Smart Tourist App (STAPP) which is a mobile travel assistant that integrates the functionalities of a traditional city card with the specificities of mobile devices.
\end{abstract}

Keywords: New Service Development, Kano Model, Analytic Hierarchy Process, Smart Tourism, Tourist Experience Evaluation.

\section{INTRODUCTION}

With the aim of enhancing and simplifying the life of people, the research community is currently dealing with the development of new models of digital technology applications. Complex systems, such as cities, could be more efficient and geographically compact with the support of digital technologies. The concept of the digital city is included within the broader concept of the 'Smart City', which is considered the metropolis of the future. The European Union (EU), in its Europe 2020 strategy, has emphasized the need to sustain 'smart, sustainable, and 
inclusive growth' that might emerge stronger from the economic and financial crisis of the coming years (COM, 2010). The term 'smart' is related to interconnection, attraction, sustainability, comfort, and social inclusion. There is now a greater need than ever to redesign cities in order to make them structurally focused on improving the welfare and quality of life of their inhabitants. A city can be defined as 'smart' if its economic activities, mobility, environmental resources, relationships between people, homelessness, and administration are managed intelligently. In addition, a city can be defined as 'smart' when its investments in human and social capital and in traditional (transport) and modern (ICT) infrastructures fuel sustainable economic development and a high quality of life. As a result, being 'smart' is not linked solely to the presence of information and communications infrastructure. Human, relational, and social capitaltogether with the preservation of the environmental system - are important factors of urban growth.

The development of new models of 'Smart Cities', based on ICT, sustainable growth, social inclusion, and quality of life in urban areas, should not overlook the tourism industry. Cities should be considered 'touristic products' that need to be managed with a long-term strategy and vision.

In order to develop a high-quality tourist offer, there is a need for modern and efficient infrastructure that facilitate accessibility and mobility, and a need also for educational, cultural, and leisure institutions that could foster the spreading of the 'knowledge economy' (Ferri et al., 2014). A new model of 'Smart Tourism' should emerge as an innovative view of tourism supported by the new digital technologies, oriented towards improving and simplifying the tourist experience. The spreading of smart technologies has great potential for the tourism industry. Mobile technologies play a key role (among digital technologies) on account of their simplicity, widespread availability, pleasure of use, and usefulness. With the pervasive adoption of smartphones and tablets, mobile services and applications have gained mainstream popularity.

In spite of the global economic crisis, the mobile Internet devices sector is among the few which experiences continuous and fast growth. And it is rapidly becoming a daily presence in the life of people who want to be "always on". On a global level, around 1.4 billion people owned and used smartphone monthly 
worldwide in 2013. The research company eMarketer forecasts that smartphone penetration will jump from 5\% of the global population in 2009, to 25\% in 2014 . And by the end of 2017, more than one-third of all people around the globe will be smartphone users (eMarketer, 2014).

Mobile technologies enable a new way of travelling as 'digital tourists,' for whom the travelling experience is empowered by the information and entertainment coming (though not exclusively) their new 'travel buddy': the mobile technology device (Palumbo et al, 2014). Tourism industry must not lose the chance to attract this new kind of empowered tourist.

Mobile apps have the potential to personalize the tourist experience, by augmenting reality and integrating tourist offerings into a much broader range of use-case scenarios (Palumbo et al, 2013). Hence, understanding the antecedents of the quality of the digital tourist experience becomes pivotal in predicting the success or failure of a mobile tourism service. Indeed, experience is an antecedent of tourist satisfaction. The challenge for these digital services is to rapidly supply customer-oriented content at low (or zero) cost, following the growing expectations of their customers and users (Dominici, 2009a, 2009b). Technological services can fail in the market if they do not consider in advance the needs of the users and their willingness to use the service. Before launching new services, it is important to assess if there is demand for them and what users' needs and requirements are. Our research purpose is to promote a user-centered innovation approach in the tourism industry, involving users throughout the design of a new service development, may contribute to the acceleration of the spread and adoption of mobile and contactless technologies by companies and tourists.

The paper is organized as follows: first we give a theoretical framework outlining the current state-of-the-art of research in the field of Smart Tourism and Near Field Communication technology, with particular attention paid to its impact on the tourism industry; then we briefly describe the proposed methodology and we apply this mixed model to our case study describing the new service designed for tourists visiting cultural cities. We conclude by pointing out the relevance and the limitation of our research, and the possibilities of further research. 
The results of our analysis can be relevant for tourism managers to plan strategic and operative activities, for researcher in the field of tourism marketing, for application developers, and for all those concerned with touristic and cultural heritage issues.

\section{BACKGROUND}

\subsection{The mobile tourist experience}

Today, we carry our smartphones everywhere we go, using them for communication, maps, and many other purposes that make our lives easier. The mobile and wireless technology incorporated into smartphones and other mobile devices has an increasing impact on everyday life. Smartphones and mobile devices can play a key role in mediating the tourist experience (Wang et al., 2012) since tourists use mobile technology before, during, and after the travel.

Smartphones and mobile devices can help travellers' decision-making process through the provision of easy access to information anywhere and at any time, and by enabling travellers to learn of new travel opportunities and to become more familiar with destinations (Brown and Chalmers, 2003; O'Brien and Burmeister, 2003; Rasinger et al, 2007).

"Imagine a traveller driving on an Interstate highway in America. With the assistance of a GPS-enabled iPhone, he/she accesses Google Map for driving directions. Rock music is played through the car's stereo system with the streaming music coming from the Spotify app on the phone. With a little help from the embedded search engine, he/she locates a restaurant of one of his favourite brands 20 miles away along the highway; and, fifteen minutes later arrives at the restaurant and instantly checks in through the Foursquare app equipped with the location-awareness capabilities. His/her status is immediately updated so that he/she can now interact with friends through various social networks, such as Facebook and Twitter." (Wang and Xiang 2012: 309).

There is a flourishing field of academic studies concerning the impact of mobile technology on the tourist experience (e.g. Kramer et al., 2007; Kim et al, 2008; Paris, 2012; Rasinger et al, 2009; Tussyadiah and Zach, 2012; Wang et al, 
2012; Wang et al, 2014). According to several authors (Buhalis and Law, 2008; Ricci, 2010; Wang et al, 2012; Palumbo et al. 2013; Palumbo and Dominici, 2014), smartphones and other mobile devices are becoming the most promising area for promoting technological innovation in the tourism sector. Wang, Xiang and Fesenmaier (2014) have noticed that the use of mobile technology in everyday life can spill over to the travel context. Dickinson et al. (2014) stated that the smart phone ubiquitous capability to link people to remote information repositories, exchanging location-based data and social information has made it a powerful tool for tourists. Thanks to the usefulness and the rapid diffusion of mobile devices in the tourism context, a plethora of mobile phone apps are emerging: tourist-specific apps, travel and transport related apps, socialnetworking apps, and apps extending social networking to vehicles and the ‘things' people need (Dickinson et al., 2014).

\subsection{Near Field Communication Technology and mobile wallet}

Near Field Communication (NFC) technology and mobile wallets are two powerful tools that can be incorporated into mobile devices to augment the travel experience. NFC has been defined as a proximity technology for data transfer without physical touch (operating with a range of up to $5 \mathrm{~cm}$ and a speed of 400 $\mathrm{kbit} / \mathrm{sec}$ ), which has evolved from Radio Frequency Identification (RFID) (Ok et al., 2010; Pesonen and Horster, 2012). NFC allows people to interact with objects through the help of a smartphone or other mobile device, revolutionizing daily habits. According to the International Air Transport Association (IATA, 2009), NFC is the third wave in the mobile telephony revolution, following mobile voice and text and mobile Internet communication (Egger, 2013).

The main advantage of NFC technology is its dematerialization-meaning that all the information normally included in physical devices (badges, credit cards, access keys, etc.) is stored inside the smartphone. Other advantages of this technology include the speed of information exchange and the convergence of the offline and the online world (by making available more information about the products in a physical store). Tourism is a promising area for developing this technology. Pesonen and Horster (2012: 11) have stated, "NFC has been predicted to be one of the next big things in technological progress and it can 
potentially have a huge effect on both the tourism business and tourism research".

The mobile wallet, or multiwallet, is a type of application for smartphones that integrates a physical wallet, money, payment cards, keys, and other cards, and which enables users to simultaneously employ all these cards using only a smartphone equipped with Near Field Communication technology.

A mobile wallet can be used for different purposes: mobile payment, mobile ticketing, vouchers, and couponing, digital identity, loyalty cards, and customized and geolocalized offers. According to Fischer (2009), an electronic wallet could replace credit, debit, transportation, access, and loyalty cards, and could also be used for vending machines. NFC technology, by enabling smartphones and other mobile devices to become mobile wallets, will simplify and considerably improve customer experience.

According to Madlmayr and Scharinger, 2010, NFC technology and mobile wallets may be useful for a number of tourist purposes: access authorization, loyalty programs, mobile payment, Bluetooth and Wi-Fi configuration, VCard transfer, Smart Poster, data exchange, OTA (over-the-air) provisioning, ticket upload, and money top-up (i.e., preloading money). Kneißl et al. (2009) affirm that NFC technology may be useful not only for payments and ticketing but also for social purposes in the tourism industry. For example, it could allow users to share places they have visited on social networks by simply moving their NFC device close to in-location tags. Ok et al. (2010) have imagined NFC-based services in hotels, for example, as automated check-in systems.

Ho and Chen (2011) studied the impact of NFC technology on user satisfaction. They hypothesized that restaurants could customize menus and offer special discounts to guests equipped with NFC-enabled devices, improving their experience and enhancing their satisfaction.

Fischer stated:

«The customer sees an advertisement, likes what he/she sees, waves the phone, and orders the product right there. Imagine arriving at an airport, going to a hotel advertisement board, choosing a hotel that looks good, and waving the phone reader over the tag; the phone either offers the URL to go 
to the reservations Webpage or just dials the number, and stores the address in your phone. You confirm with the hotel. You then go to your rental car and wave the phone over the navigation system for a peer-to-peer connection; the address you got from the board is transferred into the navigation system, and you are on your way.» (2009: 24).

\subsection{The Kano Model (KM)}

Kano Model was proposed in 1984 by Noriaki Kano. The Kano model allows measuring and evaluating the level of customer satisfaction that emerges from the positive spread between perceived quality and expected quality.

Kano provides a useful and practical approach for categorizing product or service attributes according to the customers' perception and the impact on customer satisfaction. The main differences between the Kano Model and the other widely used models of customer satisfaction - such as SERVQUAL (Parasuraman et al, 1988) and the Critical Incident Approach (Hayes, 2008; Dominici and Guzzo, 2010) — are that the Kano Model:

- can be applied both before the consumer experience (in order to design the customer's ideal product or service) and after (to measure customer satisfaction). As Chaudha et al. (2011) have indicated, the Kano Model is a useful tool for identifying customer needs and transforming these into design requirements, engineering specifications, and ultimately production details.

- does not assume the existence of a linear relationship between product/service performance and customer satisfaction. Kano noticed that customer requirements are not equivalent. Some requirements, in fact, are capable of generating more satisfaction than others. Moreover, customer satisfaction is not always proportional to the functionality of the product or service, implying that higher quality does not necessarily lead to higher satisfaction.

- is useful and simple, being able to efficiently and effectively provide relevant strategic and operative information. 
Kano classified product and service attributes into three primary categories (based on their impact on customer satisfaction):

- Must-be attributes (basic factors or dissatisfiers if absent): these requirements are considered by the customer as basic factors, and their presence thus will not increase the satisfaction level significantly. Their absence, however, will cause extreme dissatisfaction.

- One-dimensional attributes (performance factors): these factors cause satisfaction when their performance is high, and dissatisfaction when their performance is low. These attributes are linear and symmetric (as shown in Figure 1), because they are typically connected to customer's explicit needs and desires. The company should try to be competitive here.

- Attractive attributes (satisfiers or excitement factors): these requirements cause customer satisfaction if delivered, while they do not cause dissatisfaction if they are not delivered. Their presence strengthens the competitive advantage of the firm because such factors increase the value of the product or service as perceived by the customer. The company can use these factors to distinguish itself from its competitors in a positive way.

In addition, Kano identified two categories of requirements that refer to the characteristics of the product or service what customers perceive as indifferent (or even adverse):

- Indifferent: the customer does not care about whether this feature is present or not.

- Reverse: the customer does not desire this kind of product requirement, and its presence causes a great level of dissatisfaction; its absence determines satisfaction.

Figure 1 depicts the relationship between the presence of an attribute of quality and customer satisfaction.

The Kano model has been applied to the topic of tourism many times. Lee and Chen (2006) applied the Kano two dimensional quality model to Taiwan's hot spring hotels service quality evaluation. Changa and Chen (2011) integrated the Kano model with the Quality Function Deployment (QFD) to explore customers' 
brand contacts in the hotel business; Yang et al. (2009), used the Kano model to examine the frequency of use of service items, to propose a strategic pricing model for hotels. Pawitra and Tan (2003) integrated Kano's model, SERVQUAL, and quality function deployment in order to evaluate the image of Singapore from the perspective of tourists from Indonesia. Moreover, Chang, Chen and Hsu (2012) have applied a framework composed by the Kano model and the Importance-Satisfaction model with the aim to identify the critical brand contact elements of a tourist destination. Nevertheless, little research has been done about the application of Kano Model in the field of tourist experience design.

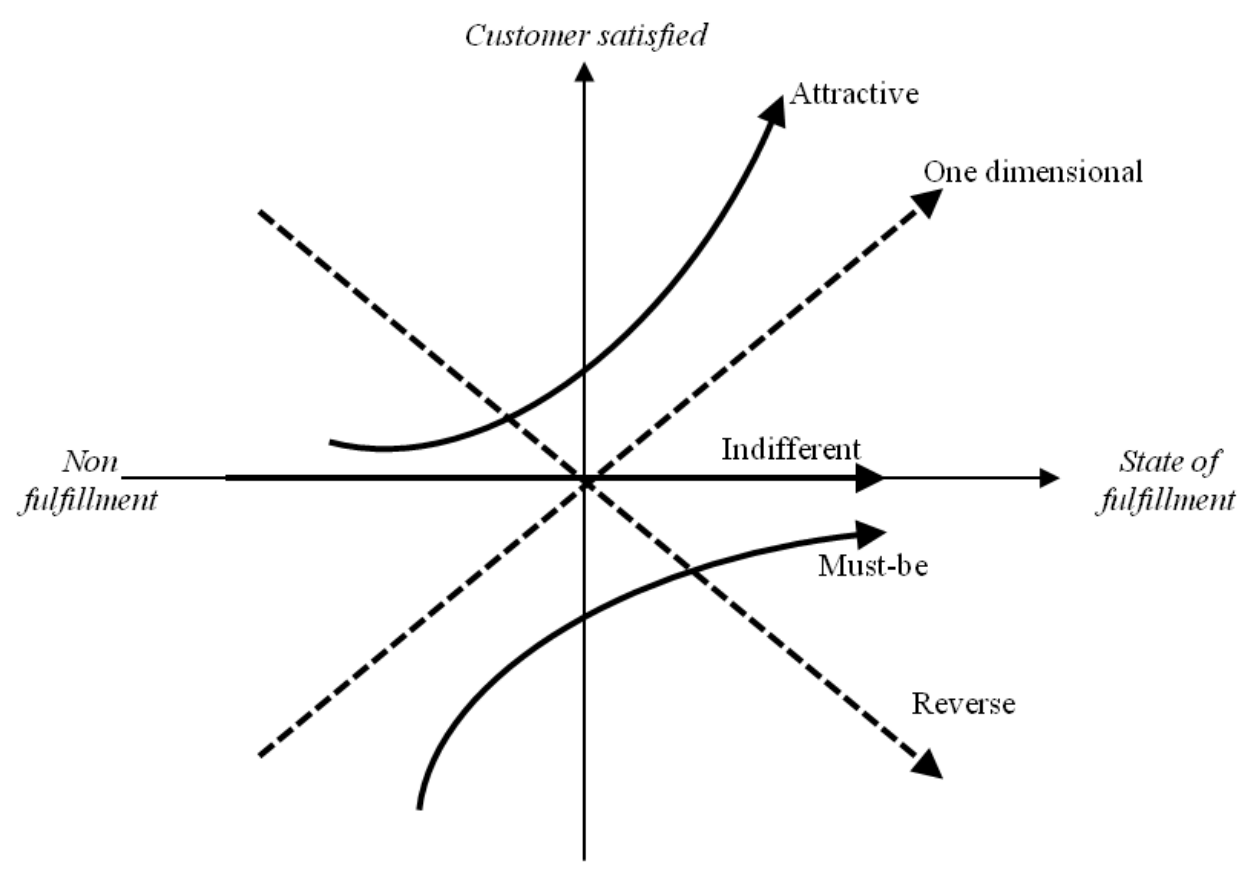

Customer dissatisfied

Figure 1. Kano diagram (adapted from Kano et al., 1984). 


\subsubsection{Implementing the Kano Model}

The implementation of measurement in the Kano Model follows four steps:

1. identification of the customer's needs;

2. development of the questionnaire;

3. administration of interviews;

4. interpretation and evaluation of the results.

The identification of customer's needs can be implemented via individual interviews or through focus-group interviews with members who already know the product or service. Even if individual interviews are characterized by reduced time and cost, focus groups are usually more useful, because the interaction among the members of the group facilitates the emergence of latent needs. Typically, individual interviews are helpful in identifying one-dimensional quality attributes, while focus groups help identify attractive elements. Shiba et al. (1993) formulated five questions which are useful in this phase for investigating customers' needs:

- What associations does the customer make when using product or service $\mathrm{X}$ ?

- Which problems, defects, or complaints does the customer associate with the use of product or service $\mathrm{X}$ ?

- Which criteria does the customer take into consideration when buying product or service $\mathrm{X}$ ?

- Which new features or services would better meet the expectations of the customer?

- What would the customer change in product or service $X$ ?

After the customers' needs and the ideal features of the product or service have been identified, it is possible to prepare the questionnaire. The questionnaire according to the Kano methodology is characterized by pairs of questions for each customer requirement:

- How would you feel if requirement $\mathrm{Y}$ were present in the product or service? (Functional form of the question). 
- How would you feel if requirement $\mathrm{Y}$ were not present in the product/service? (Dysfunctional form of the question).

For each functional and dysfunctional question, the customer can select one of five alternative answers as expressions of different degrees of perception: 1. I like it that way; 2. It must be that way; 3. I'm neutral; 4. I can live with it that way; 5. I dislike it that way.

For each questionnaire, the answers to each functional-dysfunctional question pair are cross-referenced using a matrix formulated by Kano, and the perceptions are thus evaluated into quality dimensions (M: must-be requirement; I: indifferent; $\mathrm{R}$ : reverse; O: one-dimensional; A: attractive; Q: questionable requirements ${ }^{1}$ ). To each pair of customer perceptions, the matrix associates one requirement category. Thus, if the customer replies "I'm neutral" to the functional question and "I dislike it this way" to the dysfunctional question, the requirement (according to the Kano matrix) is a "must-be" requirement.

In order to administrate questionnaires, is necessary to identify the sample to interview and the mode of administration (online, paper, or orally).

Finally, having administered the questionnaires and collected the data, it is possible to proceed to the interpretation and evaluation stage.

\subsubsection{Interpretation and evaluation of results}

The last phase in the development of the Kano Model is the interpretation and evaluation of the results. There are two subsequent and complimentary methods for doing this (Matzler and Hinterhuner, 1998): Evaluation by frequency and the $\mathrm{M}>\mathrm{O}>\mathrm{A}>\mathrm{I}$ rule.

Evaluation by frequency: each requirement is classified as into one of the five categories of perception, and then listed on the basis of the highest frequency.

Evaluation by the $\mathbf{M}>\mathbf{O}>\mathbf{A}>\mathbf{I}$ rule: it is a hierarchical rule of quality-category importance that can be used to design a product or service. The most important requirements that cannot be lacking in a product or service are the must-be

\footnotetext{
${ }^{1}$ Questionable requirements (Q) are those for which it is unclear how customers consider them. This can happen because of ambivalent responses due to a misunderstanding of the question, or erroneously filling-out the questionnaire.
} 
requirements, then the one-dimensional ones, then the attractive ones, and least importantly, the indifferent requirements.

\begin{tabular}{|c|c|c|c|c|c|c|}
\hline & \multicolumn{5}{|c|}{$\begin{array}{l}\text { Dysfunctional question: } \\
\text { How do you feel if the requir ement } Y \text { is not present? }\end{array}$} \\
\hline & & $\begin{array}{l}\text { Ilike it that } \\
\text { way }\end{array}$ & $\begin{array}{l}\text { It must-be } \\
\text { that way }\end{array}$ & I'm neutral & $\begin{array}{l}\text { Ican live } \\
\text { with it that } \\
\text { way }\end{array}$ & $\begin{array}{l}\text { Idislike in } \\
\text { that way }\end{array}$ \\
\hline \multirow{5}{*}{$\begin{array}{l}\text { Functional } \\
\text { Question: } \\
\text { How do you feel } \\
\text { if the requirement } \\
\text { Yis present? }\end{array}$} & I like it that way & Q & A & A & A & $\mathrm{O}$ \\
\hline & $\begin{array}{l}\text { It must-be that } \\
\text { way }\end{array}$ & $\mathrm{R}$ & I & I & I & M \\
\hline & I'm neutral & $\mathrm{R}$ & I & I & I & M \\
\hline & $\begin{array}{c}\text { Ican live with it } \\
\text { that way }\end{array}$ & $\mathrm{R}$ & I & I & I & M \\
\hline & $\begin{array}{l}\text { Idislike in that } \\
\text { way }\end{array}$ & $\mathrm{R}$ & $\mathrm{R}$ & $\mathrm{R}$ & $\mathrm{R}$ & Q \\
\hline & & \multicolumn{5}{|c|}{ RESULTS } \\
\hline & & \multicolumn{3}{|c|}{$\begin{array}{l}\mathbf{M}=\text { must-be requir ement } \\
\mathbf{O}=\text { one dimensional requirement } \\
\mathbf{A}=\text { attractive requir ement }\end{array}$} & \multicolumn{2}{|c|}{$\begin{array}{l}\mathbf{I}=\text { indiffer ent requirement } \\
\mathbf{R}=\text { reverse requir ement } \\
\mathbf{Q}=\text { questionable requirement }\end{array}$} \\
\hline
\end{tabular}

Figure 2. Kano Evaluation matrix (adapted from Kano et al., 1984).

\subsection{The Analytic Hierarchy Process (AHP)}

The AHP is a multicriterion decision-making (MCDM) method that was proposed by Saaty in 1972 (Ishizaka and Labib, 2011). It is commonly used to find weights for customer preferences. AHP compares progressively different alternatives and quantifies their contribution to the main objective. This technique allows a hierarchical order to be defined among the requirements identified by the Kano Model. The method is particularly valuable for dealing with complex problems, such as the development of new services, in that it helps simplify decision-making processes that contain multiple conflicting and subjective criteria (Ishizaka and Labib, 2011).

Many authors have applied this methodology in the context of tourism. Lai and Vinh (2013) used it in order to measure the effectiveness of the promotional activities of tourist destinations and to decide upon a promotional strategy that appropriately parallels the desired destination attributes and destination image. Das and Mukherjee (2008) have developed an AHP-QFD framework for 
designing a tourism product which takes care of the touristic needs of tourists. Papić-Blagojević et al (2012) have applied the AHP in analyzing the behaviour of tourists in the earlier periods with consideration of their preferences and they ranked the tourist attractions relying on their past experience. The study of Lee $e t$ al (2011) assumes particular significance for our purpose. Indeed, they adopted our same methodology, combining the Kano model and the Analytic Hierarchy Process, to propose a service requirements management method for value cocreation among the stakeholders for a medical tourism service system.

The AHP method is based on four steps:

1. Problem modelling: In this phase, the problem is defined and hierarchically structured into multiple levels, which consist of the main criteria, the associated subcriteria, and the competing alternatives (Wang and Hsueh, 2013).

2. Pairwise comparison: according to psychological studies, evaluating two alternatives is more efficient and is simpler than simultaneously evaluating all alternatives. The method is based on a series of pairwise comparisons among the different alternatives, in which each is given a rating of relative importance. This comparison ends with a percentage being awarded. The sum of all percentage weights must equal $100 \%$. The AHP method allows decision makers to express an opinion on two alternatives using a ratio scale (verbal appreciation) and not an interval scale (numerical judgment). Comparisons are recorded in a reciprocal matrix, where the generic element $\mathrm{a}_{\mathrm{ij}}$ is the relative judgment between the alternative $i$ and the alternative $j$ :

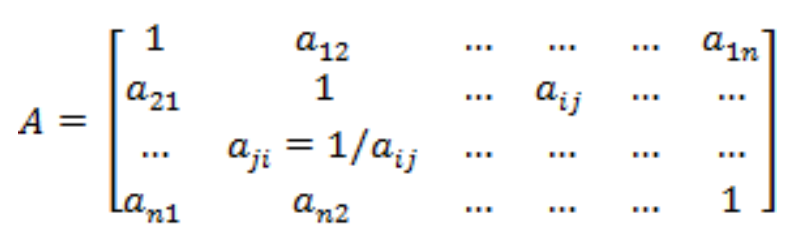

3. Judgment scales: pairwise comparisons can be expressed either in natural language or using a nine-point scale that allows natural language judgments to be converted into integers from one to nine. 
4. Derivation of priority: The last and most important phase is the derivation of a set of priorities $\mathrm{p}_{1}, \ldots, \mathrm{p}_{\mathrm{n}}$. One of the most common methods adopted to derive priorities is the mean of the row (Ishizaka and Labib, 2011).

\begin{tabular}{|l|l|l|}
\hline Importance & Definition & Explanation \\
\hline 1 & Equal importance & Two factors equally contribute to the objective. \\
\hline 3 & $\begin{array}{l}\text { Somewhat more } \\
\text { important }\end{array}$ & Experience and judgment slightly favour one over the other. \\
\hline 5 & $\begin{array}{l}\text { Much more } \\
\text { important }\end{array}$ & Experience and judgment strongly favour one over the other. \\
\hline 7 & $\begin{array}{l}\text { Very much more } \\
\text { important }\end{array}$ & $\begin{array}{l}\text { Experience and judgment very strongly favour one over the } \\
\text { other. Its importance is demonstrated in practice. }\end{array}$ \\
\hline 9 & $\begin{array}{l}\text { Absolutely more } \\
\text { important }\end{array}$ & $\begin{array}{l}\text { The evidence favouring one over the other is of the highest } \\
\text { possible validity. }\end{array}$ \\
\hline $2,4,6,8$ & & When compromise is needed. \\
\hline
\end{tabular}

Table 1. Saaty's semantic scale (Saaty, 1990).

\section{RESEARCH QUESTIONS, OBJECTIVES, AND PROPOSED METHODOLOGY}

In this paper, we adopt a mixed-method approach, according to a multiphase exploratory mixed-method design, which builds a quantitative study on the results of a qualitative study (Teddlie and Tashakkori, 2009; Creswell and Plano Clark, 2011). The mixed-method approach is based on the strength of both quantitative (QUAN) and qualitative (QUAL) research methods, and may provide a complete picture of the research problem.

In the exploratory mixed-method design, the methods are implemented sequentially (QUAL $\rightarrow$ QUAN). The QUAL strand is considered exploratory, and is followed by further testing and verification during the QUAN phase. 
- Phase 1: In the first phase of this research, we aim to answer to the following research question: "What are the explicit and latent needs of tourists who adopt mobile technology in their travel experience?" For this purpose, we apply an explorative qualitative analysis through in-depth, unstructured interviews and focus groups involving a sample of tourists who are already familiar with mobile apps for tourism. This phase aims to identify the tourists' main explicit and latent needs relating to the mobile travel experience, and the ideal features of the new service. This is also the first step of Kano Model.

- Phase 2: In the second phase of this research, we aim to answer to the following research question: "How should the new service be designed in order to satisfy tourists and enhance their travel experience?". For this purpose, we apply an integrated approach combining the Kano Model (KM) and the Analytic Hierarchy Process (AHP), in order to transform the identified tourists' needs into designed requirements and to thus develop a new tourist service based on the drivers of tourist satisfaction.

In answering these questions, we propose a new service, called the "Smart Tourist App" (STAPP), specifically designed for digital-technology-enhanced tourist experiences. STAPP's features are the integration of mobile and contactless technologies (Near Field Communication technology) and support for mobile wallets. Service development is an integrated result of design, manufacturing, research and development, and compliance with the Voice of Customers (VoC). Involving the end user throughout the design of a new service development is highly recommended, if the aim is to define a technological offer that meets the user's needs, desires, and constraints. For this reason, we integrate two existing methodologies, the Kano Model and the Analytic Hierarchy Process (AHP). To apply this mixed methodology, we use qualitative data collected through questionnaires administered in different rounds to a panel of tourists visiting the Italian cities of Palermo and Rome over a period of 3 months (MarchMay 2014). 


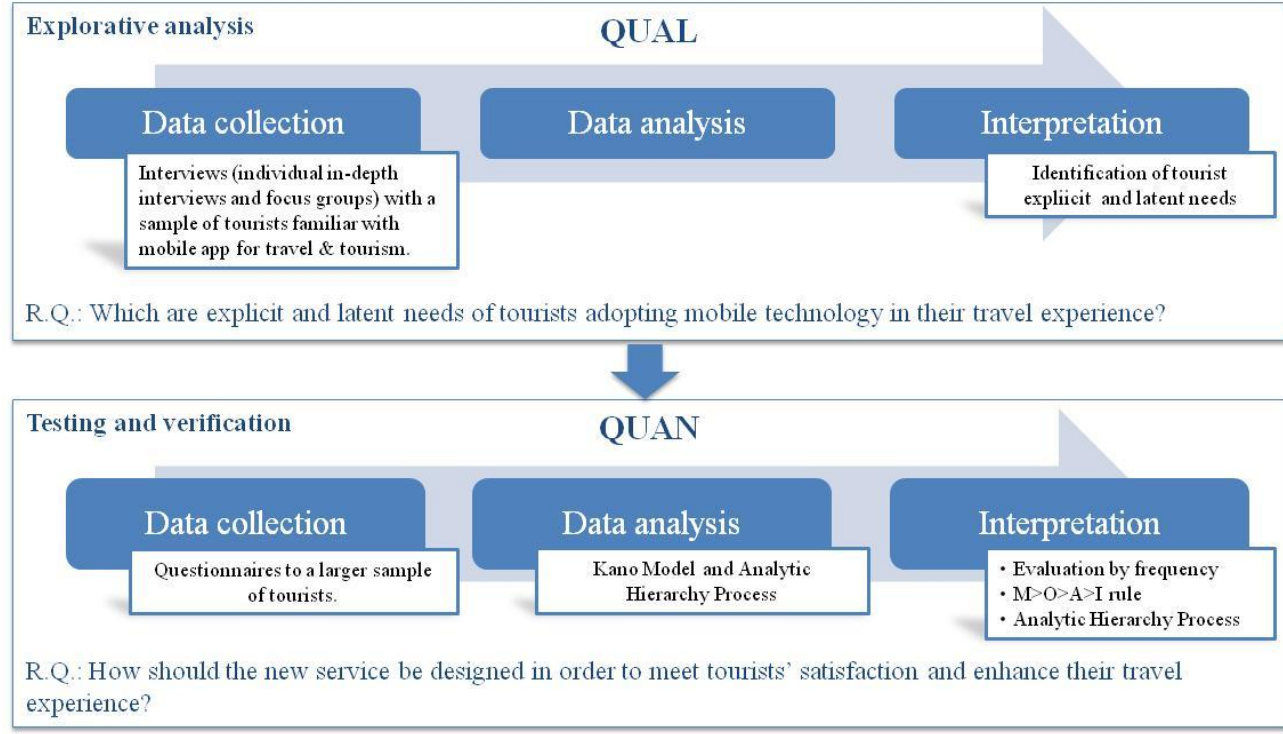

Figure 3. Research questions and methodology

\section{THE NEW SERVICE DEVELOPMENT IN THE TOURISM INDUSTRY: THE SMART TOURIST APP (STAPP)}

We now describe an application of the proposed methodology in the field of smart tourism. We aim to develop a new service concept, Smart Tourist App (STAPP), to act as a mobile travel assistant that integrates the functionalities of a traditional city card with the specific features of mobile devices (digital voice service, text messaging, email, web browsing, portable media players, low-end compact digital cameras, pocket video cameras, GPS navigation, touch screen, QR code reader and proximity technology such as Near Field Communication). STAPP should provide a wide range of customized, interactive, geo-located services to tourists.

First, we use the KM to elicit explicit and latent requirements and to divide them into the five groups based on their impact on customer satisfaction (must-be, one-dimensional, attractive, indifferent, and reverse). Then we calculate the relative importance of all the requirements in the same category identified by KM using AHP.

\section{Step 1: Identification of the needs and expectations of tourists}

Prior to distributing the questionnaires to the tourists, we held five focus-group interviews (in groups of five people) and 10 unstructured interviews with tourists 
who had already had experience with mobile city guide applications. The focus group meeting began with the respondents answering the questions formulated by Shiba et al. (1993) using their previous experiences as a guide.

Using their answers and the debate that followed, we have been able to identify seventeen expected features, which have been grouped into five main areas, as shown in Table 2 (Content management services; Location-based services; Mobile wallet; Social; Accessibility and usability).

\section{Step 2: Development of the questionnaire}

Following the identification of the requirements, we prepared the questionnaire in order to determine the nature of these requirements. Our questionnaire consisted of two parts:

- Personal information (gender, age, place of origin, qualification, and profession), mobile device ownership, and mobile app experience.

- 34 questions in functional and dysfunctional form investigating the nature of the 17 requirements identified in step 1 . The questions were grouped into a number of classes to facilitate the overall comprehension of the survey.

\begin{tabular}{|l|ll|}
\hline Content management services & 1. & Multimedia information \\
\hline Location based services & 2. & Recommendations for personal routes \\
& 3. & Geo-located map \\
& 4. & Geo-located audio tours \\
& 5. & Augmented reality \\
\hline \multirow{2}{*}{ Sobile wallet } & 6. & Mobile payment \\
& 7. & Mobile ticketing \\
& 8. & Loyalty cards, coupon and voucher \\
& 9. & Integration with TripAdvisor \\
& 10. & Virtual postcards social sharing \\
& 11. & Geo-location social sharing \\
\hline \multirow{2}{*}{ Accessibility and usability } & 12. & Travelogue \\
& 13. & Free download \\
& 14. & Multilingual option \\
& 15. & Service available off-line \\
& 16. & Friendly and efficient user interface \\
& 17. & Compatibility with different operating systems \\
\hline
\end{tabular}

Table 2: Smart Tourist App requirements, as identified by users. 


\section{Step 3: Administration of the KM questionnaire and sample characteristics}

We administered 250 questionnaires to a sample of Italian tourists visiting the cities of Palermo and Rome. The first round of questionnaires was administered both online and in printed form over a period of 2 months: March and April 2014. After screening the collected questionnaires 240 questionnaires (out of 250) were considered valid (96\%).

The sample consisted of $35 \%$ tourists living in the North, $28 \%$ in the Centre, and $38 \%$ in the South of Italy. As for sex distribution, 53\% of the respondents were male, and $47 \%$ were female. The average age of the respondents was 42 years old. In terms of educational level $53 \%$ of respondents declared that they had a bachelor's degree, $29 \%$ a high school diploma, $12 \%$ a master's degree, and $6 \%$ a $\mathrm{Ph} . \mathrm{D}$. With regard to work $33 \%$ of the respondents were employees, $11 \%$ retirees, $15 \%$ self-employed, $24 \%$ students and $17 \%$ unemployed.

$53 \%$ of the respondents owned more than one mobile device (smartphone and/or tablet or hybrid devices, etc.) and use them regularly; $40 \%$ owned a mobile device and use it habitually; $3 \%$ owned a mobile device but don't use it regularly; the remaining $4 \%$ of respondents did not own a mobile device but were planning to buy one in the future.

Among the mobile device owners $96 \%$ of respondents have downloaded and experienced at least one mobile application. Only $30 \%$ of the respondents were familiar with mobile city guide apps.

\section{Step 4: KM results and discussion}

Following the data collection we proceeded to classify each requirement. The output of this classification might prove to be particularly relevant for tourist app developers because it could allow them to establish a hierarchical order of requirements. It could then be used to design the mobile app according to the tourists' needs and desires, thus helping to achieve higher levels of customer satisfaction. We calculated the total number of responses for each requirement, using the Kano evaluation matrix (figure 2) to identify the categories of the questionnaire responses. 


\section{Evaluation by frequency}

We used the evaluation by frequency method to evaluate the results. In We determined the category of each requirement on the basis of the maximum frequency obtained, as shown in Table 3. The questionable results had very low frequencies. So the questionnaire can be concluded to have had a high level of reliability.

First of all, there are three requirements that are considered to be must-be by respondents. All of these requirements are related to the accessibility and usability of the app. First, a mobile app for tourists should possess a multilingual option, in order to allow all tourists to use it (many of the visitors to Italian cities are foreign). The app should also have a friendly and efficient user interface, so as to allow it to spread easily among less experienced users. Another must-be is compatibility with different operating systems, in order to allow most potential users to run the app. All these requirements are mandatory, so their presence is strongly recommended. Their lack will cause high dissatisfaction levels. However, their presence does not increase the level of customer satisfaction, because users take them for granted.

We found four one-dimensional requirements. The presence of these requirements is proportional to customer satisfaction; hence, the mobile app should have them. The first of these is related to content management services: the option to download multimedia information about places to visit (such as ongoing and planned exhibitions, announcements, events, timetables with scheduled events, and explanatory information about monuments and artworks). Using Near Field Communication technology tourists can tap their smartphone on a tag incorporated into the object (e.g : in the form of cards or smart posters) or affixed to the surface and in this way receive the appropriate multimedia information quickly and easily.

The second one-dimensional requirement is a geolocation map. This is a feature that runs on GPS-enabled mobile devices and provides a richer experience than could be received on a desktop PC because the data sent and received change as the physical location of the tourist changes. Geolocation maps allow real-world locations (such as restaurants, museums, and events) to be related to the users' 
location, meaning that the user can receive location-aware offers. Geo-located maps are ideal tools for guiding tourists through unfamiliar environments, showing virtual paths and directional arrows to facilitate both indoor and outdoor pedestrian and car navigation.

Another one-dimensional requirement is the possibility of storing, updating, and managing digital loyalty cards, coupons, and vouchers directly on the smartphone through a mobile wallet. The last one-dimensional requirement is that the app should be free to download because people are not willing to pay to buy a mobile app for travel and tourism if they do not know its value and usefulness in advance.

The results also show that tourists consider four requirements to be attractive. Tourist app developers are free to decide whether to include these requirements in their apps, since their absence does not decrease the level of customer satisfaction, while their presence strongly increases it. These kinds of requirements are useful for differentiating a mobile app from its competitors, for increasing the perceived value of the app, and for significantly improve the travel experience. The first attractive requirement is the ability to receive recommendations for personal routes, including the ability to create a customized city tour (e.g. own interests, available time, trip length, visit type).

The second attractive requirement is the augmented reality. Augmented reality is a disruptive technology that will influence almost every aspect of our technological life. It is based on the integration of digital 3D content into the real world. Augmented reality applications aimed at tourists will enrich the real world with interactive virtual information that allow visitors to unfamiliar locations to identify the most important and interesting points of interest and to learn more about their surroundings. Augmented reality is a key tool for implementing the futuristic idea of the Internet of Things - a term originally proposed in 1999 by Kevin Ashton to refer to a world of networked smart objects (Ashton, 2009). As a means of highlighting interesting features or of bringing history to life, augmented reality has great potential in the travel sector. It can deliver vast quantities of location-based information to visitors, as well as virtual tour guides and convincing interactive previews of the tourist attractions. One additional attractive 
requirement is integration with TripAdvisor, which would allow the app to display the latest reviews, ratings, awards, and local information.

Service requirement

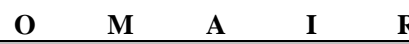

Category

Content management services

1. Multimedia information

$\underline{\mathbf{1 0 8}} \quad 48 \quad 48 \quad 36 \quad 0 \quad 0$

One dimensional

2. Recommendations for personal routes

$\begin{array}{llllll}52 & 28 & 80 & 76 & 4 & 0\end{array}$

Attractive

\section{Location based services}

\begin{tabular}{|c|c|c|c|c|c|c|c|}
\hline 3. Geo-located map & $\underline{88}$ & 60 & 56 & 36 & 0 & 0 & One dimensional \\
\hline 4. Geo-located audio tours & 36 & 12 & 56 & $\underline{128}$ & 8 & 0 & Indifferent \\
\hline 5. Augmented reality & 68 & 12 & $\underline{100}$ & 56 & 4 & 0 & Attractive \\
\hline \multicolumn{8}{|l|}{ Mobile wallet } \\
\hline 6. Mobile payment & 20 & 8 & 72 & $\underline{108}$ & 28 & 4 & Indifferent \\
\hline 7. Mobile ticketing & 44 & 4 & 88 & $\underline{96}$ & 8 & 0 & Indifferent \\
\hline 8. Loyalty cards, coupon and voucher & $\underline{72}$ & 24 & 68 & 52 & 24 & 0 & One dimensional \\
\hline \multicolumn{8}{|l|}{ Social } \\
\hline 9. Integration with TripAdvisor & 44 & 36 & $\underline{85}$ & 75 & 0 & 0 & Attractive \\
\hline 10. Virtual postcards social sharing & 24 & 4 & 60 & $\underline{144}$ & 8 & 0 & Indifferent \\
\hline 11. Geolocation social sharing & 20 & 16 & 36 & $\underline{148}$ & 20 & 0 & Indifferent \\
\hline 12. Travelogue & 32 & 4 & 80 & $\underline{108}$ & 16 & 0 & Indifferent \\
\hline \multicolumn{8}{|l|}{ Accessibility and usability } \\
\hline 13. Free download & $\underline{108}$ & 104 & 28 & 0 & 0 & 0 & One dimensional \\
\hline 14. Multilingual option & 92 & $\underline{96}$ & 32 & 20 & 0 & 0 & Must-be \\
\hline 15. Service available off-line & 76 & 44 & $\underline{88}$ & 28 & 4 & 0 & Attractive \\
\hline $\begin{array}{l}\text { 16. Friendly and efficient user } \\
\text { interface }\end{array}$ & 76 & $\underline{96}$ & 24 & 44 & 0 & 0 & Must-be \\
\hline $\begin{array}{l}\text { 17. Compatibility with different operating } \\
\text { systems }\end{array}$ & 84 & $\underline{116}$ & 20 & 16 & 4 & 0 & Must-be \\
\hline
\end{tabular}

Table 3: Requirements by frequency

The final attractive requirement for the app is offline availability: this feature guarantees that the app can be used even if there is no Wi-Fi connection. This requirement is very important for foreign tourists who usually do not have a subscription to Italian Internet service providers. Near Field Communication technology has the great advantage that it allows users to access information and exchange data without an Internet connection. 
App developers should not invest in fulfilling indifferent requirements, because these have no impact on customer satisfaction. We found six indifferent requirements. The first of these is geo-located audio tours, which would allow audioguides containing detailed information about the tourist's. The other three indifferent requirements are related to the social networking: tourists are not interested in sharing virtual postcards, their location, or a travelogue within their social networks.

The last two indifferent requirements are mobile payment and mobile ticketing. The first of these refers to the opportunity of using the mobile device as a credit or debit card at the point of sale automatically saving the receipt in the mobile wallet and updating the travel budget. Mobile ticketing is the ability to buy transport tickets through mobile devices, receiving a virtual boarding pass for a public transport system. These requirements, related to the mobile wallet, are probably considered indifferently because people still are not familiar with these services or do not trust mobile commerce sufficiently to consider using them. Nevertheless, according to several studies, mobile payment and mobile ticketing represent a promising and profitable future for mobile technology (School of Management Politecnico di Milano, 2014). Hence, tourist app developers should not neglect them.

\section{$M>O>A>I$ rule}

By considering the frequencies of the results and by applying the hierarchical $\mathrm{M}>\mathrm{O}>\mathrm{A}>\mathrm{I}$ rule, some practical indications emerge. If tourism app developers wish to design a mobile app to suit tourists' needs, they will first of all ensure the presence of the must-be requirements - that is, multilingual options, friendly and efficient user interface, and compatibility with different operating systems.

Once these must-be requirements have been fulfilled, app developers should then provide the one-dimensional requirements - namely multimedia information, geo-located map, loyalty cards, coupons, and vouchers, and a free download.

If additional resources are available, the app could be enriched by the four attractive requirements that have been identified: recommendations for personal routes, augmented reality, integration with TripAdvisor, and off-line availability. 
Tourist app developers should avoid investing resources in the indifferent requirements - namely, geo-located audio tours, mobile payment, mobile ticketing, and social sharing of virtual postcards, location, and travelogues.

\section{Step 5: AHP problem definition and development of the questionnaire.}

One of the main limitations of the $\mathrm{M}>\mathrm{A}>\mathrm{O}>\mathrm{I}$ rule is that it does not allow a hierarchical order to be defined within the same category. For this reason, having grouped the requirements into the five clusters identified by KM, we used AHP to explore the hierarchical order among the requirements in the same category (mustbe, one-dimensional, attractive) (Table 4). We did not consider indifferent or reverse requirements, since their implementation is not recommended.

\begin{tabular}{|l|l|}
\hline Must-be & $\begin{array}{l}\text { M1: Multilingual option } \\
\text { M2: Friendly and efficient user interface } \\
\text { M3: Compatibility with different operating systems }\end{array}$ \\
\hline One dimensional & $\begin{array}{l}\text { O1: Multimedia information } \\
\text { O3: Loyalty cards, coupon and voucher } \\
\text { O4: Free download }\end{array}$ \\
\hline Attractive & $\begin{array}{l}\text { A1: Recommendations for personal routes } \\
\text { A2: Augmented reality } \\
\text { A3: Integration with TripAdvisor } \\
\text { A4: Service available off-line }\end{array}$ \\
\hline
\end{tabular}

Table 4. AHP requirement list.

We calculated the importance value and the pairwise comparison of the selected requirements identified in the problem definition (Fig. 4). 
Level 1

New service development

Overall objective

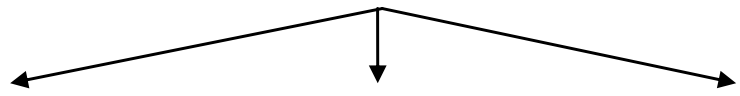

Level 2

Group criteria

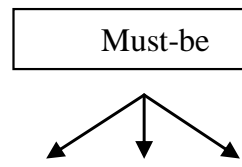

One dimensional

Attractive

Level 3

\begin{tabular}{l|l|l|} 
M1 & M2 & M3 \\
\hline
\end{tabular}

\begin{tabular}{|l|l|l|l|}
\hline $\mathrm{O} 1$ & $\mathrm{O} 2$ & $\mathrm{O} 3$ & $\mathrm{O} 4$ \\
\hline
\end{tabular}

\begin{tabular}{l|l|}
$\mathrm{A} 1$ & $\mathrm{~A} 2$ \\
\end{tabular}

A3

A4

Criteria

Figure 4. Decision hierarchy.

In the AHP questionnaire we asked users to assign an importance value for each requirement, on a scale of 1 (some importance) to 9 (extremely importance). A pairwise comparison between all requirements belonging to the same category was then carried out.

The main differences between the Kano questionnaire and the AHP questionnaire are summarized in Table 5.

\begin{tabular}{|l|l|l|l|}
\hline Schemes & Corresponding questions & Scales & Respondents \\
\hline KM & $\begin{array}{l}\bullet \quad \text { How do you feel about X if } \\
\text { it is fulfilled? } \\
\begin{array}{l}\text { it is unfulfilled? } \\
\text { AHP }\end{array}\end{array} \begin{array}{l}\text { Linguistic (5-point) } \\
\text { preferred to X2? }\end{array}$ & Customers \\
\hline
\end{tabular}

Source: adapted from Wang and Hsueh, 2013.

Table 5. Illustration of questionnaires design. 


\section{Step 6: Administration of the AHP questionnaire}

We administered 240 questionnaires by email to the same sample of Italian tourists already interviewed in step 3.

For this second round of investigation the questionnaires were administered over a period of 1 month (May 2014). After screening the collected questionnaires, 229 questionnaires (out of 240) were considered valid (95\%).

\section{Step 7: AHP results and discussion}

Having completing the customer survey, the results were processed using AHP. The pairwise comparison of requirements in each category (must-be, onedimensional, and attractive) is shown in Tables 6, 7, and 8.

Moreover, the number shows the relative importance of the two requirements (for instance, value 5 for the pair M2 and M1 means that M2 is considered 5 times more important than M1.

\begin{tabular}{|c|c|c|c|}
\hline Requirements & M1 & M2 & M3 \\
\hline M1 & 1 & $1 / 5$ & $1 / 3$ \\
\hline M2 & 5 & 1 & 5 \\
\hline M3 & 3 & $1 / 5$ & 1 \\
\hline
\end{tabular}

\begin{tabular}{|c|c|c|c|c|}
\hline Requirements & $\mathbf{O 1}$ & $\mathbf{O 2}$ & $\mathbf{O 3}$ & $\mathbf{O 4}$ \\
\hline $\mathbf{O 1}$ & 1 & 7 & 3 & $1 / 7$ \\
\hline $\mathbf{O 2}$ & $1 / 7$ & 1 & 5 & $1 / 9$ \\
\hline $\mathbf{O 3}$ & $1 / 3$ & $1 / 5$ & 1 & $1 / 9$ \\
\hline $\mathbf{O 4}$ & 7 & 9 & 9 & 1 \\
\hline
\end{tabular}

\begin{tabular}{|c|c|c|c|c|}
\hline Requirements & A1 & A2 & A3 & A4 \\
\hline $\mathbf{A 1}$ & 1 & $1 / 5$ & 3 & $1 / 9$ \\
\hline $\mathbf{A 2}$ & 5 & 1 & 7 & $1 / 9$ \\
\hline $\mathbf{A 3}$ & $1 / 3$ & $1 / 7$ & 1 & $1 / 9$ \\
\hline $\mathbf{A 4}$ & 9 & 9 & 9 & 1 \\
\hline
\end{tabular}

Table 6-7-8. Sample pair-wise matrixes 


\section{Step 8: The results of AHP: derivation of priorities}

Based on the "mean of row" method described by Ishizaka and Labib (2011), we calculated the weights of each requirement and the final weighted order of the requirements for a tourist mobile app. This is shown in Table 9.

\begin{tabular}{|l|l|}
\hline $\mathbf{M}$ & $\begin{array}{l}\text { Friendly and efficient user interface }(0.69) \\
\text { Compatibility with different operating systems }(0.21) \\
\text { Multilingual option }(0.10)\end{array}$ \\
\hline \multicolumn{1}{|c|}{$>$} \\
\hline O & $\begin{array}{l}\text { Free download }(0.65) \\
\text { Multimedia information }(0.20) \\
\text { Geo-located map (0.11) } \\
\text { Loyalty cards, coupon and voucher }(0.05)\end{array}$ \\
\hline & \multicolumn{2}{|c|}{$>$} \\
\hline A & $\begin{array}{l}\text { Service available offline }(0.66) \\
\text { Augmented reality (0.21) } \\
\text { Recommendations for personal routes }(0.08) \\
\text { Integration with TripAdvisor }(0.04)\end{array}$ \\
\hline
\end{tabular}

Table 9. Hierarchical order among requirements derived from KM and AHP

\section{CONCLUSIONS, LIMITATIONS, AND FURTHER RESEARCH}

We believe that the next decade and beyond will see a qualitative shift in the travel and tourism experience, with the emergence of an era of 'Smart Tourism' that will transform the way people experience travel.

NFC technology and mobile wallets hold great promise for tourism marketing and advertisement. Through mobile-based promotion, they will become increasingly popular tools (Okazaki and Hirose, 2009) and could contribute to the diffusion of mobile coupons and customized discounts (Pesonen and Horster, 2012).

We investigated and assessed the perceived impact of mobile technology in augmenting and simplifying the tourist experience. We found and measured some relevant drivers of the explicit and latent needs of tourists adopting mobile 
technology in their travel experience. Using these data, we proposed a new smart service designed to meet tourists' satisfaction and enhance their travel experience.

From a theoretical perspective the main innovativeness of this study is the application, in the context of tourism, of a composite model that integrate two existing methodologies, the Kano Model and the Analytic Hierarchy Process (AHP).

We have introduced our prototype for a new service application for smart tourism, called the Smart Tourism App (STAPP). This meets customers' expectations by offering a wide range of services, such as the provision of tourist information, mobile payment, mobile ticketing, location-based services, social sharing, and the management of loyalty, bonus, and membership cards.

The main managerial implication of this study is the proposal of a simple and practical model useful to identify and order the requirements a product or a service according to the drivers of customer satisfaction.

In addition, the results of our analysis can provide some practical hints on how to design a mobile app for tourists visiting Italian cities. Tourism app developers will first of all ensure the presence of the must-be requirements - that are, according to the hierarchical order identified by the AHP model, multilingual options, friendly and efficient user interface, and compatibility with different operating systems.

Once these must-be requirements have been fulfilled, app developers should then provide the one-dimensional requirements - namely multimedia information, geo-located map, loyalty cards, coupons, and vouchers, and the free download.

If additional resources are available, the app could be enriched by the four attractive requirements that have been identified: recommendations for personal routes, augmented reality, integration with TripAdvisor, and off-line availability.

Tourist app developers should avoid investing resources in the indifferent requirements-namely, geo-located audio tours, mobile payment, mobile ticketing, and social sharing of virtual postcards, location, and travelogues. Although this new service concept may bring a number of benefits and new 
business opportunities to the tourism sector, there are several challenges and constraints that need to be coped with:

- STAPP should include a wide variety of heterogeneous and diversified services. This could be a barrier to implementation.

- The tourism sector is highly fragmented and is characterized by the existence of many small companies that often lack sufficient resources to invest in new technologies and infrastructure.

- In Italy the digital divide is still very high.

- Local authorities have few financial resources to invest in improving tourist offerings.

- NFC technology is still not widely known by users. In addition, in order to exploit its potential, NFC technology needs the support of other technologies - such as Wi-Fi networks. However, Wi-Fi coverage is, as yet, not guaranteed in all areas of Italy.

- The NFC standard is still struggling to establish itself and, despite its many capabilities, has been applied mainly for entertainment functions. The predicted spread of micropayments has not occurred, and alternative solutions for virtual currency exchange have been favoured: in Germany, for example, mobile payments can be made by entering a password to the smartphone or by scanning barcodes.

- The mobile payment ecosystem is still highly fragmented and insecure. Consumers and tourists may raise some privacy concerns. Nevertheless, these concerns could be solved by offering them various valuable incentives in exchange for their data.

We plan to further develop this research in the future by testing and assessing both tourists' acquaintance with and acceptance of mobile technology (with a particular focus on NFC technology and mobile wallets) and the interest (or lack thereof) of local authorities and travel, leisure, and hospitality companies in developing a range of new services based on NFC and mobile wallets. 


\section{REFERENCES}

ASHTON, K. (2009): "That 'Internet of Things' Thing, in the real world things matter more than ideas", RFID Journal. http://goo.gl/umjuJc

BROWN, B.; CHALMERS, M. (2003): "Tourism and Mobile Technology", in KUUTTI, K.; KARSTEN, E.H., et al (Eds.), ECSCW 2003: Proceedings of the eighth European conference on computer supported cooperative work, Helsinki, Finland, pp. 335-355, Klewer Academic Press.

BUHALIS, D.; LAW, R. (2008): "Progress in information technology and tourism management: 20 years on and 10 years after the Internet - The state of eTourism research", Tourism Management, vol. 29, n. 4: 609-623. http://dx.doi.org/10.1016 j.tourman.2008.01.005

CHANG, K.C.; CHEN, M.C.; HSU, C.L. (2012): "Identifying Critical Brand Contact Elements of a Tourist Destination: Applications of Kano's Model and the Importance-satisfaction Model", International Journal of Tourism Research, vol. 14, n. 3: 205-221. http://dx.doi.org/10.1002/jtr.839

CHANGA, K.C.; CHEN, M.C. (2011): “Applying the Kano model and QFD to explore customers' brand contact in the hotel business: a study of a hot spring hotel", Total Quality Management, vol. 22, n. 1: 1-27. http://dx.doi.org/10.1080/1 $\underline{4783363.2010 .529358}$

CHAUDHA, A.; JAIN, R.; SINGH, A.R.; MISHRA, P.K. (2011): "Integration of Kano's model into quality function deployment", International Journal of Advanced Manufacturing Technology, vol. 53, n. 5-8: 689-698. http://dx.doi.org/10.1007/s00170-010-2867-0

COM (2010): "EUROPE 2020. A strategy for smart, sustainable and inclusive growth. Communication from the Commission", http://goo.gl/DxS0PJ

CRESWELL, J.W.; PLANO CLARK, V.L. (2011): Designing and conducting mixed methods research. Sage Publications, Thousand Oaks (CA).

DAS, D.; MUKHERJEE, K. (2008): "Development of an AHP-QFD framework for designing a tourism product", International Journal of Services and Operations Management, vol. 4, n. 3: 321-344. http://dx.doi.org/10.1504/IJSOM 
.2008 .017297

DICKINSON, J.E.; GHALI, K.; CHERRETT, T.; SPEED, C.; DAVIES, N.; NORGATE, S. (2014): "Tourism and the smartphone app: capabilities, emerging practice and scope in the travel domain", Current Issues in Tourism, vol. 17, n. 1: 84-101. http://dx.doi.org/10.1080/13683500.2012.718323

DOMINICI, G. (2009a): "From Marketing Mix to e-Marketing Mix: a literature overview and classification", International Journal of Business Management, vol. 4, n. 9: 17-24. http://dx.doi.org/10.5539/ijbm.v4n9p17

DOMINICI, G. (2009b): E-marketing: analisi dei cambiamenti dai modelli di business al mix operativo. FrancoAngeli, Milan (IT).

DOMINICI, G.; GUZZO, R. (2010): “Customer satisfaction in the hotel industry: a case study from Sicily”, International Journal of Marketing Studies, vol. 2, n. 2: 3-12. http://dx.doi.org/10.5539/ijms.v2n2p3

EGGER, R. (2013): "The impact of near field communication on tourism", Journal of Hospitality and Tourism Technology, vol. 4, n. 2: 119-133. http://dx.doi.org/10.1108/JHTT-04-2012-0014

EMARKETER (2014): "Worldwide Smartphone Usage to Grow 25\% in 2014", Jun 11, 2014, http://goo.gl/0yKqy7

FERRI, M.A.; DOMINICI, G.; BASILE, G.; AIELLO, L. (2014): "Cultural Product Management from Environment to Territorial Context: Configuration of the Main Relationships", in AIELLO, L. (Ed.), Management of Cultural Products: E-Relationship Marketing and Accessibility Perspectives: 22-40, IGI Global.

FISCHER, J. (2009): "NFC in cell phones: The new paradigm for an interactive world", IEEE Communications Magazine, vol. 47, n. 6:22-28. http://dx.doi.org/10 $.1109 /$ MCOM.2009.5116794

HAYES, B.E. (2008): Measuring Customer Satisfaction and Loyalty, ASQ Quality Press, Milwaukee (USA).

HO, T.; CHEN, R. (2011): "Leveraging NFC and LBS technologies to improve user experiences", Paper presented at the 2011 International Joint Conference on 
Service Sciences, IEEE, Taipei (Taiwan), 25-27 May 2011, pp. 17-21. http://dx.doi.org/10.1109/IJCSS.2011.12

IATA (2009): Airline passengers call for more self-service, www.iata.org/pressroom/pr/ Pages/2007-20-11-01.aspx

ISHIZAKA, A.; LABIB, A. (2011): "Review of the main developments in the analytic hierarchy process", Expert Systems with Applications, vol. 38, n. 11: 14336-14345.

KANO, N.; SERAKU, N.; TAKAHASHI, F.; TSUJI, S. (1984): "Attractive quality and Must-be quality", The Journal of the Japanese Society for Quality Control, vol. 14, n. 2: 39-48.

KIM, D.Y.; PARK, J.; MORRISON, A.M. (2008): “A Model of Traveller Acceptance of Mobile Technology", International Journal of Tourism Research, vol. 10, n. 5: 393-407. http://dx.doi.org/10.1002/jtr.669

KNEIßL, F.; RÖTTGER, R.; SANDNER, U.; LEIMEISTER, J.M.; KRCMAR, H. (2009): "All-I-Touch as Combination of NFC and Lifestyle", Paper presented at the 1st International Workshop on Near Field Communication, IEEE, Hagenberg (Austria), 24-26 February 2009, pp. 51-55.

KRAMER, R.; MODSCHING, M.; HAGEN, K.; GRETZEL, U. (2007): "Behavioural Impacts of Mobile Tour Guides", Information and Communication Technologies in Tourism, vol. 2007, n. 2007, 109-118.

LAI, W.H.; VINH, N.Q. (2013): “An application of AHP approach to investigate tourism promotional effectiveness", Tourism and Hospitality Management, vol. 19, n. 1: 1-22.

LEE, J.; SUGUMARAN, V.; PARK, S. (2011): "Managing Service System Requirements for Korean Medical Tourism", Paper presented at the 2011 International Conference on Advancements in Information Technology, IACSIT Press, Singapore.

LEE, J.; SUGUMARAN, V.; PARK, S. (2011): "Requirements Management using Kano Model and AHP for Service Systems Design", Paper presented the 2011 IEEE Ninth International Conference on Dependable, Autonomic and 
Secure Computing, 12-14 December 2011, Sydney, pp. 1159-1166. http://dx.doi.org/10.1109/DASC.2011.188

LEE, Y.H.; CHEN, T.L. (2006): “A Kano two-dimensional quality model in Taiwan's hot spring hotels service quality evaluations", The Journal of American Academy of Business, vol. 8, n. 2: 301-306.

MADLMAYR, G.; SCHARINGER, J. (2010): "Neue Dimensionen von mobilen Tourismusanwendungen durch Near Field Communication Technologie", in EGGER R, JOOSS M (eds.) “mTourism. Mo-bile Dienste im Tourismus”. Gabler Verlag, Wiesbaden (Germany), pp. 75-88.

MATZLER, K.; HINTERHUBER, H.H. (1998): "How to make product development projects more successful by integrating Kano's model of customer satisfaction into quality function deployment", Technovation, vol. 18, n. 1: 25-38. http://dx.doi.org/10.1016/S0166-4972(97)00072-2

O'BRIEN, P.; BURMEISTER, J. (2003): “Ubiquitous Travel Service Delivery”, Information Technology \& Tourism, vol. 5, n. 4: 221-233. http://dx.doi.org/10.37 $\underline{27 / 109830503108751153}$

OK, K.; COSKUN, V.; AYDIN, M.; OZDENIZCI, B. (2010): "Current benefits and future directions of NFC services", Paper presented at the 2010 International Conference on Education and Management Technology (ICEMT), IEEE, Cairo (Egypt), : 334-338. http://dx.doi.org/10.1109/ICEMT.2010.5657642

OKAZAKI, S.; HIROSE, M. (2009): "Does gender affect media choice in travel information search? On the use of mobile Internet", Tourism Management, vol. 30, n. 6: 794-804. http://dx.doi.org/10.1016/j.tourman.2008.12.012

PALUMBO, F.; DOMINICI, G. (2014): “Augmenting tourist experience with mobile wallet and NFC technology", Paper presented at the $2^{\text {nd }}$ B.S.Lab International Symposium "Systems Thinking for a Sustainable Economy. Advancements in Economic and Managerial Theory and Practice", Rome (Italy), January 23-24, 2014.

PALUMBO, F.; DOMINICI, G. (2015): "Unraveling the Complexity of Tourist Experience with NFC Technology and Mobile Wallets", Chaos, Complexity and 
Leadership 2013, Springer Proceedings in Complexity :189-196. http://dx.doi.org/10.1007/978-3-319-09710-7_16

PALUMBO, F.; DOMINICI, G.; BASILE, G. (2013): “Designing a mobile app for museums according to the drivers of visitor satisfaction", in

VRDOLJAK RAGUZ, I., ROUSHDY, M., SALEM, A. B. M. (Eds.): Recent Advances in Business Management and Marketing, Proceedings of " 1 st International Conference on Management, Marketing, Tourism, Retail, Finance and Computer Applications (MATREFC '13)”, Dubrovnik (Croatia), June 25-27, 2013, WSEAS Press, pp. 159-166.

PALUMBO, F.; DOMINICI, G.; BASILE, G. (2014): “The Culture on the Palm Of Your Hand: How to Design a User Oriented Mobile App for Museums", in AIELLO, L. (Ed.), Management of Cultural Products: E-Relationship Marketing and Accessibility Perspectives, pp. 224-243, IGI Global.

PAPIĆ-BLAGOJEVIĆ, N.; GAJIĆ, T.; ĐOKIĆ, N. (2012): "Using Bayesian network and AHP method as a marketing approach tools in defining tourists' preferences", Turizam, vol. 16, n.1: pp. 8-19.

PARASURAMAN, A.; ZEITHAML, V.A.; BERRY, L.L. (1988): "SERVQUAL: a multiple-item scale for measuring consumer perceptions of service quality", Journal of Retailing, vol. 64, n. 1: 12-40.

PARIS, C.M. (2012): “Flashpackers: An Emerging Sub-culture?”, Annals of Tourism Research, vol. 39, n. 2: 1094-115. http://dx.doi.org/10.1016/j.annals.201 $\underline{1.12 .001}$

PAWITRA, T. A.; TAN, K.C., (2003): "Tourist satisfaction in Singapore - a perspective from Indonesian tourists", Managing Service Quality: An International Journal, vol. 13, n. 5: 399-411. http://dx.doi.org/10.1108/09604520 $\underline{310495868}$

PESONEN, J.; HORSTER, E. (2012): "Near Field Communication technology in tourism", Tourism Management Perspectives, vol. 4: 11-18. http://dx.doi.org/10.1 $\underline{016 / j . t m p .2012 .04 .001}$ 
RASINGER, J.; FUCHS, M.; BEER, T.; HOPKEN, W. (2009): "Building a Mobile Tourist Guide based on Tourists' On-Site Information Needs", Tourism Analysis, vol. 14, n. 4: 483-502. http://dx.doi.org/10.3727/108354209X125962 $\underline{87114255}$

RASINGER, J.; FUCHS, M.; HOPKEN, W. (2007): "Information Search with Mobile Tourist Guides: A Survey of Usage Intention", Information Technology \& Tourism, vol. 9, n. 3-4: 177-94. http://dx.doi.org/10.3727/109830507782166962

RICCI, F. (2010): “Mobile recommender systems", Information Technology \& Tourism, vol. 12, n. 3: 205-231. http://dx.doi.org/10.3727/109830511X1297870 $\underline{2284390}$

SAATY, T.L. (1990): "How to make a decision: the analytic hierarchy process", European Journal of Operational Research, vol. 48, n. 1: 9-26. http://dx.doi.org/10.1016/0377-2217(90)90057-I

SCHOOL OF MANAGEMENT POLITECNICO DI MILANO (2014): "Mobile payment \& Commerce: un ponte tra il mondo fisico e vituale", Politecnico di Milano, February 20, 2014, Milan (IT).

SHIBA, S.; GRAHAM, A.; WALDEN, D. (1993): A New American TQM, Four Practical Revolutions in Management. Productivity Press, Portland.

TEDDLIE, C.; TASHAKKORI, A. (2009): Foundations of Mixed Methods Research: Integrating Quantitative and Qualitative Approaches in the Social and Behavioral Sciences. Sage Publications, Los Angeles.

TUSSYADIAH, I.P.; ZACH, F. (2012): “The Role of Geo-based Technology in Place Experiences" Annals of Tourism Research, vol. 39, n. 2: 780-800. http://dx.doi.org/10.1016/j.annals.2011.10.003

WANG, C.H.; HSUEH, O.Z. (2013): “A novel approach to incorporate customer preference and perception into product configuration: A case study on smart pads", Computer Standards \& Interfaces, vol. 35, n. 5: 549-556. http://dx.doi.org/10.1016/j.csi.2013.01.002

WANG, D.; PARK, S.; FESENMAIER, D. (2012): "The role of smartphones in mediating the touristic experience", Journal of Travel Research, vol. 51, n. 4: 371-387. http://dx.doi.org/10.1177/0047287511426341 
WANG, D.; XIANG, W.; FESENMAIER, D. (2014): "Smartphone Use in Everyday Life and Travel", Journal of Travel Research: 1-12.

WANG, D.; XIANG, Z. (2012): “The new landscape of travel: a comprehensive analysis of smartphone apps", in FUCHS, M.; RICCI, F; CANTONI, L. (Eds.) "Information and communication technologies in tourism", Proceedings of the International Conference in Helsingborg, Sweden, January 25-27, 2012. pp. 308319. Vienna: Springer-Verlag.

YANG, C.C.; CHENG, L.Y.; SUNG, D.; WITHIAM, G. (2009): "Strategicpricing policy based on analysis of service attributes", Cornell Hospitality Quarterly, vol. 50, n. 4: 498-509. http://dx.doi.org/10.1177/1938965509343666 